\begin{tabular}{|c|c|}
\hline \multirow{2}{*}{$\begin{array}{l}\text { THE JOURNALOF } \\
\text { Obstetrics and Gynaecology Research }\end{array}$} & 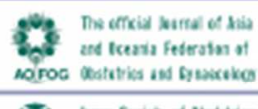 \\
\hline & 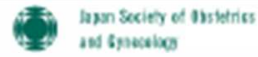 \\
\hline
\end{tabular}

\title{
Safety of elastography applied to the placenta: be careful with ultrasound radiation force
}

\begin{tabular}{|r|l|}
\hline Journal: & The Journal of Obstetrics and Gynaecology Research \\
\hline Manuscript ID & JOGR-2017-0343 \\
\hline Manuscript Type: & Letter to the Editor \\
\hline Date Submitted by the Author: & $21-$ Mar-2017 \\
\hline Complete List of Authors: & $\begin{array}{l}\text { SIMON, Emmanuel; UMR Inserm U930, University of Tours, Imaging and } \\
\text { Ultrasound; University Hospital Center of Tours } \\
\text { Callé, Samuel; UMR Inserm U930, University of Tours, Imaging and } \\
\text { Ultrasound; GREMAN, UMR CNRS 7347, University of Tours }\end{array}$ \\
\hline Keywords: & $\begin{array}{l}\text { 2.300 Obstetrics: Diagnostic Ultrasound and Prenatal Diagnosis < } 2 \\
\text { Obstetrics, 2.510 Preeclampsia/Eclampsia < 2.500 Obstetric Complications } \\
<2 \text { Obstetrics, 2.312 Doppler-Diagnostic < 2.300 Obstetrics: Diagnostic } \\
\text { Ultrasound and Prenatal Diagnosis < 2 Obstetrics, 7 Ethics }\end{array}$ \\
\hline
\end{tabular}

\section{SCHOLARONE Manuscripts}


Safety of elastography applied to the placenta: be careful with ultrasound radiation force

E.G. Simon ${ }^{1,2} *$, S. Callé e $^{1,3}$

1. UMR INSERM U930, University of Tours, Tours, FRANCE

2. Department of Obstetrics, Gynecology and Fetal Medicine, University Hospital Center of Tours, Tours, FRANCE

3. GREMAN, UMR CNRS 7347, University of Tours, Tours, FRANCE

* Correspondence:

Emmanuel G Simon, Department of Obstetrics, Gynecology and Fetal Medicine, University Hospital Center of Tours, Tours, FRANCE. E-mail: e.simo@yahoo.fr 
Dear Editor-in-Chief,

We read with interest the article entitled "Comparison of placental elasticity in normal and preeclamptic pregnant women by acoustic radiation force impulse elastosonography", and we wish to thank the authors for this work. ${ }^{1}$ We share the authors' view about the usefulness of elastography for placental exploration. However we would like to warn about the safety of ultrasound radiation force applied to pregnant women. Indeed, we do not know the exact values of the energies delivered by radiation force, whether it is Thermal Index (TI), Mechanical Index (MI), Spatial Peak-Temporal Average Intensity (ISPTA), or Spatial PeakPulse Average Intensity ( $\left.\mathrm{I}_{\mathrm{SPP} A}\right)$. Acceptable thresholds for these parameters are determined by several Societies, such as British Medical US Society (BMUS). There is a risk of tissue heating as soon as the TI is greater than 0.7 . The duration of the examination must therefore be reduced. Beyond a TI of 3 , the method should not be applied to pregnant women. The references cited by Karaman et al. do not allow the security of their system to be documented. ${ }^{1}$ The often-repeated assertion that the use of ultrasound radiation force is equivalent to that of Doppler ultrasonography is not supported by any specific data. ${ }^{2}$ Similarly, histopathological analyses of 115 placentas ex vivo by Sugitani et al. do not constitute a sufficient demonstration. ${ }^{3}$ This uncertainty about safety of ultrasound radiation force has led some authors to prefer animal experimentation, which seems to be a measure of elementary prudence. ${ }^{4}$ Even in the absence of safety data, journals increasingly accept articles reporting the use of radiation force in pregnant women. However, we believe that such jurisprudence is not entirely acceptable. We know that the calculation of the TI is difficult from a methodological point of view, and we would not want to block the use of these promising tools by an excess of precaution. While waiting for new data, we recall that some elastographic methods make it possible to avoid the use of radiation force, for example strain elastography, or transient elastography. Certainly, strain elastography gives only qualitative 
values about relative elasticity of the tissues, which constitutes imperfect information. But transient elastography provides the same results as those of Shear Wave Elastography or ARFI, i.e. Young's Modulus and Shear Wave Speed. This is the approach chosen by our team.

\section{Disclosure}

The authors declare that they have no conflicts of interest.

\section{References}

1. Karaman E, Arslan H, Çetin O, et al. Comparison of placental elasticity in normal and pre-eclamptic pregnant women by acoustic radiation force impulse elastosonography. $J$ Obstet Gynaecol Res 2016; 42: 1464-70.

2. Kılıç F, Kayadibi Y, Yüksel MA, et al. Shear wave elastography of placenta: in vivo quantitation of placental elasticity in preeclampsia. Diagn Interv Radiol 2015; 21: 202-7.

3. Sugitani M, Fujita Y, Yumoto Y, et al. A new method for measurement of placental elasticity: acoustic radiation force impulse imaging. Placenta 2013; 34: 1009-13.

4. Quarello E, Lacoste R, Mancini J, Melot-Dusseau S, Gorincour G. Feasibility and reproducibility of ShearWave(TM) elastography of fetal baboon organs. Prenat Diagn 2015; 35: 1112-6. 